EGU2020-9594, updated on 08 May 2020

https://doi.org/10.5194/egusphere-egu2020-9594

EGU General Assembly 2020

(c) Author(s) 2020. This work is distributed under

the Creative Commons Attribution 4.0 License.

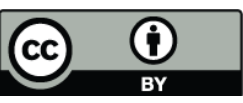

\title{
Trans- and interdisciplinary research - Running a Graduate Research School across the Atlantic Ocean
}

Christel van den Bogaard ${ }^{1,2}$ and Kirsten Laing ${ }^{3,4}$

${ }^{1}$ GEOMAR Helmholtz Centre for Ocean Research, HOSST Research School, Kiel, Germany (cbogaard@geomar.de)

${ }^{2}$ Helmholtz Ocean System Science and Technology Research School (HOSST)

${ }^{3}$ Transatlantic Ocean System Science and Technology Research School (TOSST)

${ }^{4}$ Dalhousie University, Halifax, Canada

Understanding ocean and atmosphere dynamics in the Atlantic Ocean is the goal of the HOSSTTOSST Research school "Transatlantic Ocean System Science and Technology". At the heart of the project is the introduction of science work across topics of the North Atlantic Ocean System. Our goal is motivating the young researcher to consider and engage with various aspects of ocean research beyond their own special field of research. For this we have established a weekly seminar series with video system support. It allows us to stay in contact even with an ocean between us. Being able to stay in contact, we meet once a year in person in a joint summer school, setting up topics outside the immediate research areas and have all participants work in small groups. Cosupervision of doctoral thesis and extended research exchanges at the partner University, working with the co-supervisors research group, are fundamental for the full transatlantic research experience.

The poster and our presence will give interested persons the chance to learn from our experience how to enable a good group dynamic in the research school. Providing the basics for the best interdisciplinary research. Come and learn from our experience of establishing a dynamic research network across the Atlantic. 